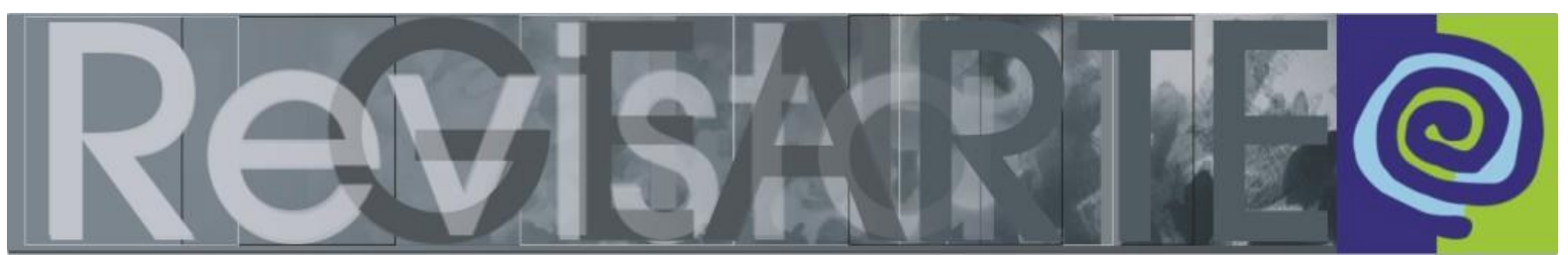

ISSN 2357-9854 | e-ISSN 2596-3198 (online)

\title{
O fazer-manual de acessórios eletrônicos sensíveis: uma abordagem interdisciplinar de arte, moda e design
}

\author{
Thatiane Mendes Duque \\ (Universidade do Estado de Minas Gerais - UEMG, Belo Horizonte, Brasil) \\ Adriano Aguiar Mol \\ (Universidade do Estado de Minas Gerais - UEMG, Belo Horizonte, Brasil)
}

\begin{abstract}
RESUMO - O fazer-manual de acessórios eletrônicos sensíveis: uma abordagem interdisciplinar de arte, moda e design - $O$ artigo apresenta desdobramentos da condução de processos artísticos e pesquisas sobre possibilidades conceituais da computação vestível e o corpo do usuário, suas emoções e afetos. Descreve uma abordagem de ensino interdisciplinar, voltada à criação de acessórios interativos com capacidades de sensoriamento do corpo e do ambiente, e sua construção manual com técnicas tradicionais que trazem a dimensão do capital cultural das artesanias. Apresenta experiências práticas, que fomentaram reflexões e estabeleceram intercâmbios a partir da construção manual de vestimentas e joias, objetos dentre os mais legítimos suportes de memórias e narrativas contemporâneas de intimidade com o corpo.
\end{abstract}

PALAVRAS-CHAVE

Acessórios sensíveis. Poéticas tecnológicas. Joias digitais.

\begin{abstract}
Wearable computing and sensible electronic accessories: an interdisciplinary approach between art, fashion and design - The article presents unfolding of research and artistic processes carried about the conceptual possibilities of wearable computing and the user's body, its emotions and affections. It describes an interdisciplinary approach in education, aimed at the creation of accessories capable of body and environment interactions, and their manufacture with traditional techniques weighing in the cultural capital of handicrafts. It presents practical experiences, which fostered reflections and established exchanges based on this manual construction of clothing and jewelry, objects among a body's most legitimate supports of memories and contemporary narratives of intimacy.
\end{abstract}

KEYWORDS

Sensitive accessories. Technological poetics. Digital jewelry.

RESUMEN — La fabricación manual de accesorios electrónicos sensibles: una aproximación interdisciplinar al arte, la moda y el diseño - El artículo presenta desarrollos en la conducción de procesos artísticos e investigaciones sobre las posibilidades conceptuales de la computación portátil y el cuerpo, las emociones y los afectos del usuario. Se describe un enfoque didáctico interdisciplinario, orientado a la creación de accesorios interactivos con capacidades sensoriales del cuerpo y el entorno, y su construcción manual con técnicas tradicionales que aportan la dimensión del capital cultural de la artesanía. Presenta experiencias prácticas, que propiciaron reflexiones e intercambios establecidos a partir de la construcción manual de prendas y joyas, objetos entre los soportes más legítimos de la memoria y narrativas contemporáneas de intimidad con el cuerpo.

PALABRAS CLAVE

Accesorios sensibles. Poética tecnológica. Joyas digitales. 


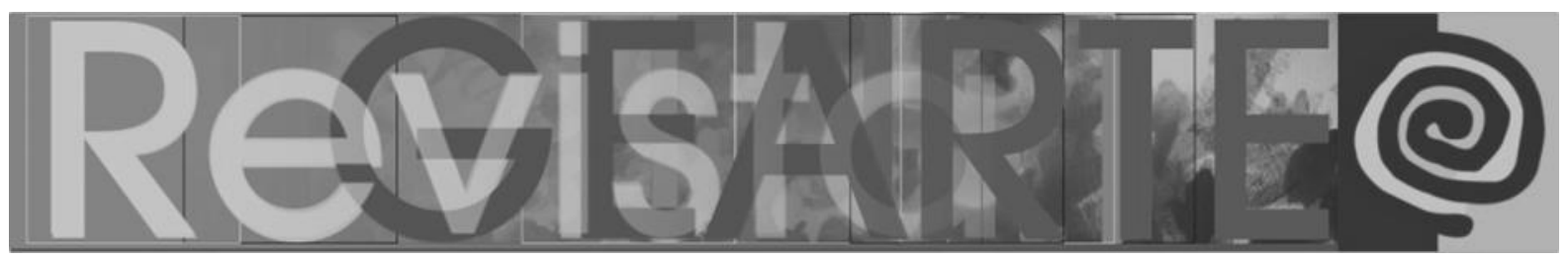

\section{Introdução}

Acessórios sensíveis são objetos capazes de interagir com o ambiente e o corpo do usuário de diferentes maneiras, ao detectar estímulos mecânicos, químicos, eletrônicos e magnéticos. Sob o termo computação vestível, cunhado em 1997 pelo pesquisador canadense Steve Mann a partir de uma perspectiva tecnológica, essa nova categoria parece solicitar diferentes denominações quando adentra no campo interdisciplinar da arte, moda e design. Se a ênfase for colocada no termo vestível, a poética do vestuário pode ser melhor expressa por termos como têxteis eletrônicos, moda tecnológica, acessórios sensíveis, joias inteligentes, bordados eletrônicos, entre outros.

Esses objetos compostos por tecidos e materiais especiais conciliam componentes eletrônicos e computacionais com o que pode ser considerado "natural". Por serem vestíveis e situarem-se próximo ao corpo, possuem a necessidade de serem confortáveis, maleáveis e laváveis; e aspectos subjetivos como as suas relações com as emoções humanas. Se apropriados na prática do fazer-manual, construídos com formas artesanais como bordado, costura e ourivesaria, essas tecnologias inspiram diferentes públicos para a imaginação de dispositivos tecnológicos mais expressivos, inventivos e inovadores.

Ao se distanciar da tendência pragmática da busca pelo aprimoramento das potencialidades físicas do corpo, volta-se o foco às possibilidades relacionadas às novas formas de percepção e de consciência, da relação com o outro e principalmente das novas potencialidades de trocas afetivas e de expressão que as tecnologias vestíveis permitem, uma vez que lidam com informações sobre um corpo em conexão e em mobilidade.

A palavra affective, em inglês, se refere ao ato de causar uma emoção forte ou afetar/influenciar. Como também em sua origem, no latim affectivu, quer dizer relação, disposição, vontade, afeição, sentimento, influência. Neste sentido, a computação afetiva é pensada como aquela que possui a qualidade de afetar e ser 


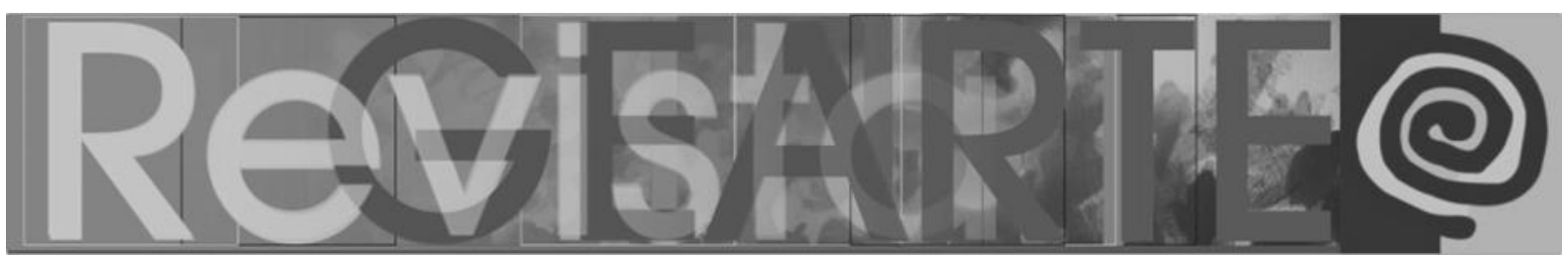

afetada, base para a interatividade. $O$ afeto é um aspecto amplamente utilizado na comunicação humana, usado naturalmente na interação entre pessoas, e assim também acontece quando interagem com computadores. Sendo assim, o objetivo da computação afetiva é que se dê aos computadores a habilidade de reconhecer e expressar emoções, fazendo com que eles se tornem mais adaptáveis em situações de interações mais naturais. Além dessa capacidade sensível aumentada, os acessórios inteligentes podem interagir ativamente com o corpo ou o ambiente através de atuadores, modificando sua cor, forma, emitindo sons, entre outras possibilidades expressivas.

Esse artigo apresenta as pesquisas conduzidas neste escopo, com o objetivo de investigar as possibilidades projetuais de dispositivos tecnológicos afetivos, bem como as possibilidades poéticas baseadas em práticas artísticas e expressivas do uso de tais dispositivos.

A hipótese é a de que, ao aproximar o objeto técnico do que pode ser considerado "natural", como as emoções humanas, em conjunto com a sua construção por formas artesanais como bordado e costura, é possível inspirar diferentes públicos para um pensamento conduzido pelo fazer manual. Em termos metodológicos, a pesquisa busca identificar formas de exibir conteúdo emocional por meio de roupas e acessórios, através do estudo sobre os tipos de interações possíveis no campo das artes visuais, moda e design.

\section{Acessórios sensíveis}

Em uma definição bem ampla, pode-se dizer que objetos técnicos vestíveis são quaisquer dispositivos capazes de potencializar as características físicas, cognitivas e/sensoriais humanas, a partir de recursos tecnológicos e informacionais (MENDES; SALLES, 2015). Muitas das pesquisas atuais sobre computação vestível estão direcionadas para o monitoramento e aumento das potencialidades físicas do corpo humano, como, por exemplo, os produtos para coletar, armazenar, processar e apresentar os estados fisiológicos das atividades 


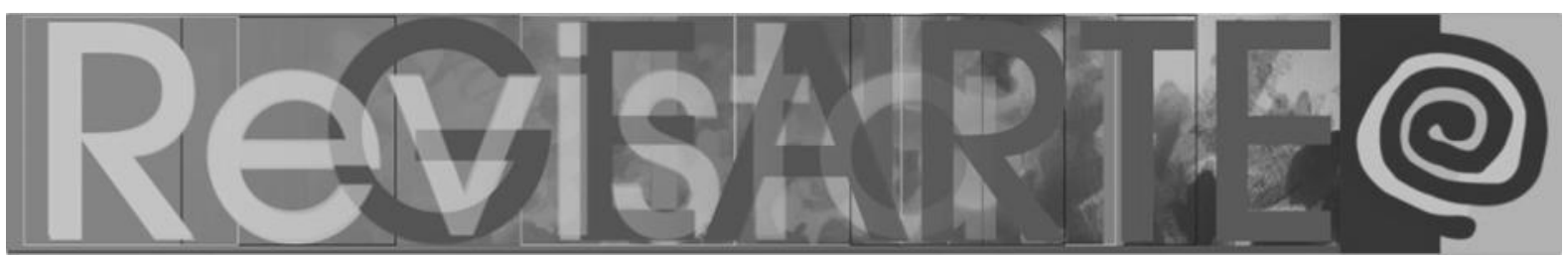

esportivas, tais como caloria queimada, níveis de atividade pessoal, entre outros dados. Ou produtos médicos, como um colete com eletrodos embutidos para o monitoramento cardíaco e pulmonar que registra os dados e os envia para um médico, que então pode fazer o ajuste da medicação de acordo com esses dados. E como dispositivo de controle, as tornozeleiras eletrônicas são utilizadas para identificação e localização por radiofrequência e GPS.

Uma forma de trabalhar com tecnologia vestível é conferir a esse tipo de dado valores estéticos, não somente tornando-a provedora de informações técnicas e impessoais nos modos de captura ou organização de dados sobre o corpo. A reflexão sobre esses mecanismos de produção de memórias e de intimidades sobre o corpo no contexto atual é uma questão que vem sendo explorada por alguns artistas e designers, como as joias eletrônicas de Jayne Wallace, que se encaixam nessa perspectiva "futura", na qual as intimidades e afetividades são compartilhadas e expressadas através de dispositivos vestíveis sobre o corpo.

Para Wallace, toda joia possui uma conexão inerente e íntima com o usuário. Elas são objetos que possuem uma carga afetiva de relações interpessoais. Neste sentido, são um canal capaz, por si só, de transporte para outros tempos, lugares e avatares, sendo ainda receptáculos de memorias e recipientes para sentimentos. A artista diz que estas características referentes às joias são inevitáveis e as ressalta quando integra tecnologias digitais nos seus objetos de joalheria. Seu trabalho Journeys entre nós, de 2012, é um projeto composto por um par de colares digitais interativos e sensíveis ao toque. $\mathrm{O}$ toque em um deles faz com que o segundo trema levemente. Essa interação é um "eco tátil" que pode refletir afetos e o desejo de proximidades com outras pessoas que estão longe. 


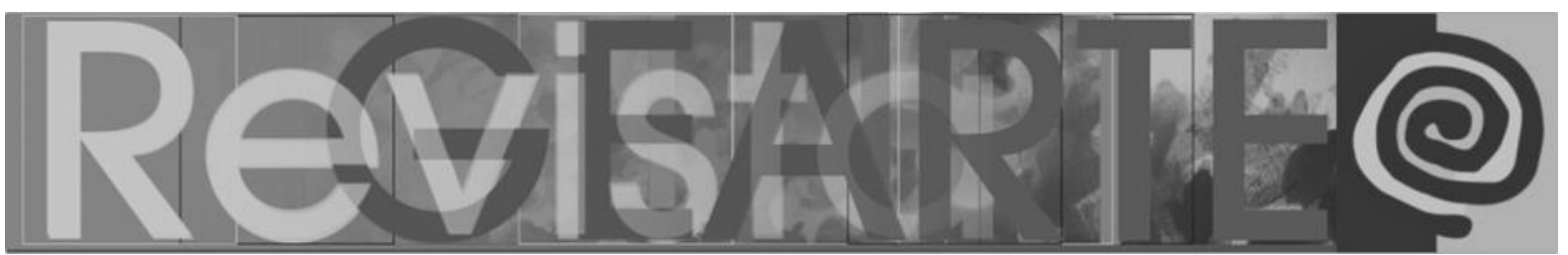

Figura 1 - Journeys entre nós
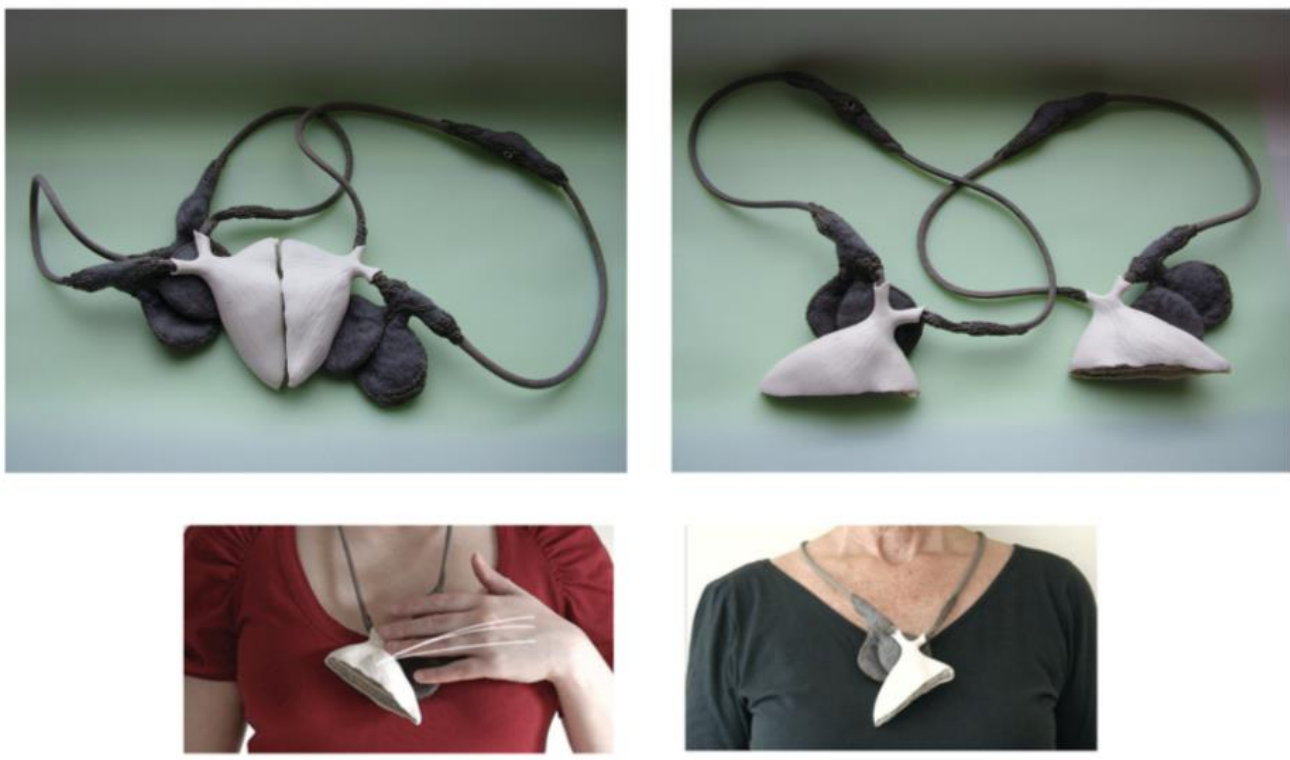

Fonte: Jayne Wallace (2018).

Pensadores como Rosalind Picard e Steve Mann também desenvolvem pesquisas sobre a subjetividade nas relações de afeto com as vestimentas tecnológicas em relação com o corpo humano, a privacidade e a criação de narrativas pessoais desenvolvidas por meio desses dispositivos. Picard (1998) é pioneira no campo da computação afetiva, campo de estudo que aborda o desenvolvimento de sistemas computacionais que lidam com a captura, interpretação e expressão da emoção humana. A computação afetiva combina pesquisa sobre a emoção humana com a lógica das máquinas. Há algumas décadas atrás não se relacionava aspectos da emoção com máquinas, pois acreditava-se que, por serem as máquinas constituídas por um conjunto de regras e as emoções não serem consideradas científicas, não se via uma relação entre a emoção humana e o pensamento racional, os argumentos lógicos e as hipóteses testáveis por meio de experimentos repetitivos. Atualmente essas barreiras foram rompidas, e pode-se constatar um crescente interesse por parte da comunidade cientifica em otimizar a interpretação de emoções e possibilitar comunicações mais naturais entre máquinas e seres humanos. Para isso torna-se premente estudos 


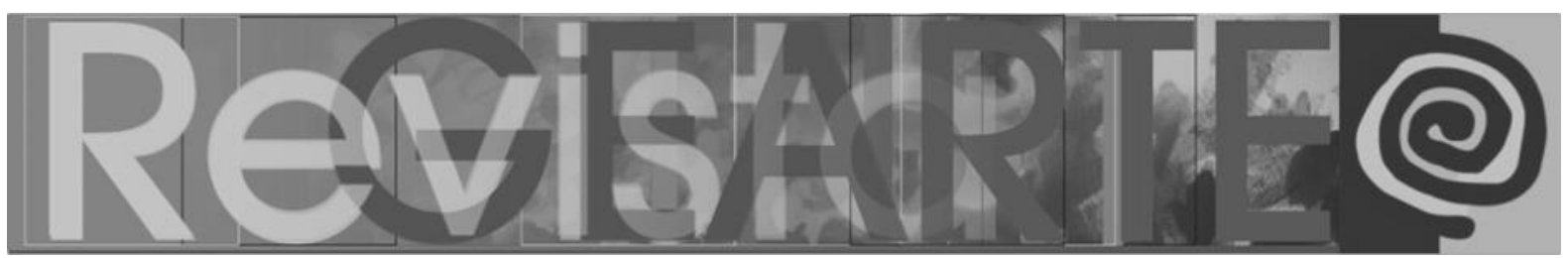

sobre a cognição humana que envolvam razão e emoção na criação de sistemas computacionais, que possam ter habilidades de reconhecer e comunicar emoções.

Esse contexto é mais importante ainda no mundo contemporâneo, no qual o corpo humano se tornou expandido nas suas misturas, nas suas potências, remodelado, multiplicado, ressignificado, híbrido e fluido (VILLAÇA, 2011). Tais características foram propiciadas pelos novos modos de vida que emergiram nas últimas décadas, como por exemplo as baseadas na hipercomunicabilidade propiciada pelas telecomunicações e a virtualização do corpo.

A moda também instaura de modo efêmero o redesenho do corpo contemporâneo: recorta, fragmenta, expande e alonga determinadas partes, através de camadas de tecidos. A roupa, tendo como suporte o corpo, tem sua união ideal, torna-se sua segunda pele. Esta, por sua vez, soma ao corpo outra camada capaz de atribuir a ele novas formas, silhuetas e contornos (CASTILHO, 2004). Nisso há uma relação que muito interessa: a capacidade das roupas de transformarem o corpo, comunicando novas subjetividades e intimidades. Pois trata-se de uma reação em simbiose, em que a roupa e o corpo funcionam concomitantemente. Para McLuhan (1964), as roupas são uma extensão da pele. Acredita-se que as roupas, quando unidas às tecnologias, vão além, pois elas podem fabricar novas subjetividades e comportamentos humanos. $O$ autor propõe ainda que a instrumentalização do homem é uma extensão dele próprio, sendo assim a roupa é um importante instrumento de análise para que se possa entender o ser humano. Para entender o corpo humano no mundo contemporâneo é necessário situá-lo em um contexto em que há necessidades criadas e demandadas pela autovigilância, a exposição de intimidades em redes sociais e a conexão com outros corpos. Para se tornar atuantes e críticos diante deste panorama é necessário identificar o que se quer, o que se quer mudar e o que se quer para os corpos dos indivíduos. O corpo e a roupa devem acompanhar e não se distrair com apenas as tendências de um "corpo físico perfeito", de uma "intimidade editada e externizada". Mas, sim, buscar acompanhar um corpo 


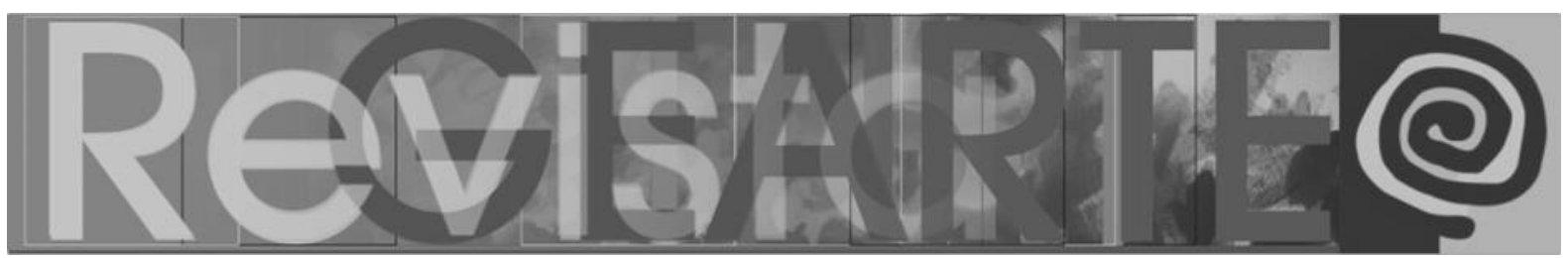

híbrido, comunicacional, expandido, e mais "sensível". É preciso achar uma roupa que permita desprender os corpos das telas de computadores e celulares, a fim de que não se atrofiem.

Steve Mann (1997) afirma que o computador pessoal não conseguiu realizar o seu objetivo de ser integrado totalmente ao dia a dia do usuário, o que poderia ser feito através de um dispositivo vestível. Este dispositivo teria como características básicas permitir a mobilidade do usuário, sem impedir a realização de outras ações como caminhar ou trabalhar durante o uso; não monopolizar a atenção do usuário, mas estar sempre atento/vigilante e acessível independentemente da interação; e ainda que esse objeto técnico tenha autonomia em relação ao seu usuário.

Os dispositivos vestíveis, ao capturarem dados do ambiente e do corpo, fazem com que esses dados se tornem imediatamente acessíveis, tal como aconteceu com os relógios, que se integraram ao corpo em 1907, tornando-se pulseiras capazes de medir o tempo, com a vantagem de proporcionar essa informação sem mobilizar em demasia a atenção do usuário em movimento.

A computação vestível de hoje encontra antecedentes nestes dispositivos, e por isso não se trata de uma tecnologia de todo contemporânea, mas que vem tornando-se mais potente, no sentido de ler e guardar informações sobre o corpo e o ambiente. Ela também é mais adaptada à pele, ao incorporar formatos menos rígidos, mais flexíveis, macios e confortáveis, assim vem se destacando das experiências que a antecederam.

Desta forma, computadores vestíveis afetivos possibilitam o aprimoramento na interação humano-computador, ao oferecer a habilidade de reconhecer e expressar emoções. Picard (1998) ressalta que a computação afetiva pode ajudar a responder perguntas, como por exemplo sobre o que é a emoção e como ela atua. Como atesta a autora, são perguntas ainda sem respostas. Em sua opinião, pesquisas neste campo contribuem para melhor entendimento da emoção 


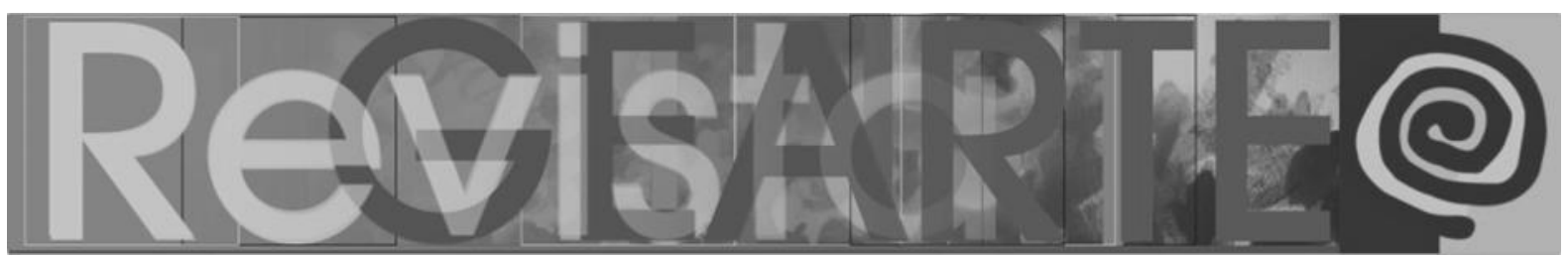

humana, tanto empírica quanto teórica, pois promovem a compreensão sobre como a tecnologia direciona e exerce influência no desenvolvimento humano.

Como já citado, a pesquisa que fomentou esse artigo visa identificar e ampliar formas de exibir conteúdo emocional por meio de roupas e acessórios, através do estudo sobre os tipos de interações possíveis. Para isso torna-se necessário o entendimento de como mapear e criar padrões de afetos por meio de computadores vestíveis. Neste sentido, Picard (1998) traz algumas pistas, nas cinco principais características que todo computador vestível afetivo precisa ter: (a) o comportamento do sistema parece semelhante às emoções humanas; (b) o sistema responde a estímulos ; (c) gera emoções com base no entendimento de situações, com base em objetivos, padrões, preferencias e expectativas; (d) possui experiência emocional (percepção cognitiva e psicológica); (e) imita a cognição humana e suas funções físicas (memória, decisão, planejamento, interesse, aprendizado, preocupação e motivações, prioridades, funções do sistema imunológico, combinação e variação de sentimentos, regulação e adaptação).

A vestimenta pode ser vista como uma testemunha de intimidade por sua estreita relação com o corpo, visto que é capaz de gravar emoções e sentimentos como medo, estresse e tensão através não só do suor, de manchas e rugas, como também de outras marcas do tempo e de utilização.

Objetos como pulseiras, relógios e joias inteligentes podem monitorar e oferecer diferentes informações, tais como batimentos cardíacos, contagem de passos, temperatura, e outros dados, coletados como um rastro da intimidade fornecida pelo contato com o corpo do usuário.

A computação vestível, por essa capacidade, torna-se então uma tecnologia de memória e, como hipótese, acredita-se que as tecnologias vestíveis e afetivas possibilitam mapear, configurar e moldar essas evidências sobre as emoções, identidade e história, além de ampliar as potencialidades dos sentidos. Nesta 


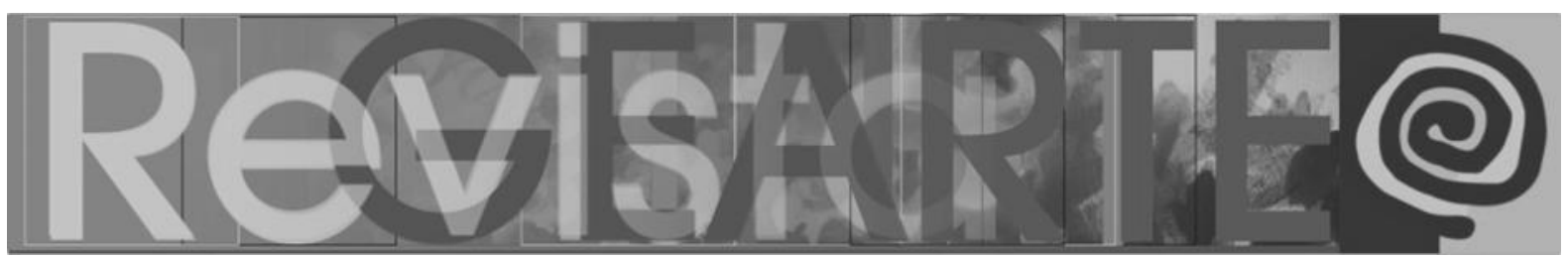

perspectiva, computadores vestíveis afetivos tornam-se ferramentas de auxílio para entendimento do ser humano.

Segundo Wallace (2007), existe um risco em combinar funcionalidades da computação nesses objetos vestíveis: fechar a categoria de joias digitais de uma maneira que as reduz ao status de meros gadgets; objetos a serem consumidos, usados por pouco tempo e depois descartados como lixo. A artista propõe então obras que discorrem sobre a longevidade e durabilidade dos vínculos pessoais, com o suporte da ourivesaria. Para a artista, esse ofício essencialmente artesanal fornece meios conceituais e empáticos de abordar uma gama de questões experimentais que ampliam a relevância e o valor das tecnologias emergentes.

Na categoria de acessórios sensíveis, uma dimensão adicional é relativa ao capital cultural da joalheria. Esses objetos de adorno corporal têm função simbólica, além da prática, relacionadas aos aspectos comunicacionais de distinção, proteção e sedução (SOARES, 2002). Hoje, o produto joia, por meio da abordagem sistêmica do design, conjuga desde os aspectos mais tradicionais, como a valorização do saber fazer artesanal, até as vantagens das novas tecnologias, como o ganho de produtividade, aumento de precisão e complexidade formal. Assim se ampliam as possibilidades conceituais e criativas no desenvolvimento desses objetos que mesclam projeto e artesania.

$\mathrm{Na}$ joalheria artesanal, em que todas as etapas da produção são normalmente feitas por um mesmo profissional, o produto final resulta de sua capacidade artística e técnica, objeto da manualidade e do domínio do processo produtivo da ourivesaria, conjunto de técnicas de fundição de ligas, preparação de chapas e fios para conformação de objetos de adorno pessoal. No campo da joalheria, está localizada a joalheria de autor e a joia-arte. Esse campo tem sua linguagem formal e técnicas exclusivas, como a granulação (pequenas esferas), filigrana (fios), solda e fundição por cera perdida, que são técnicas praticadas desde o início dessa atividade humana. Técnicas de ourivesaria como processos 


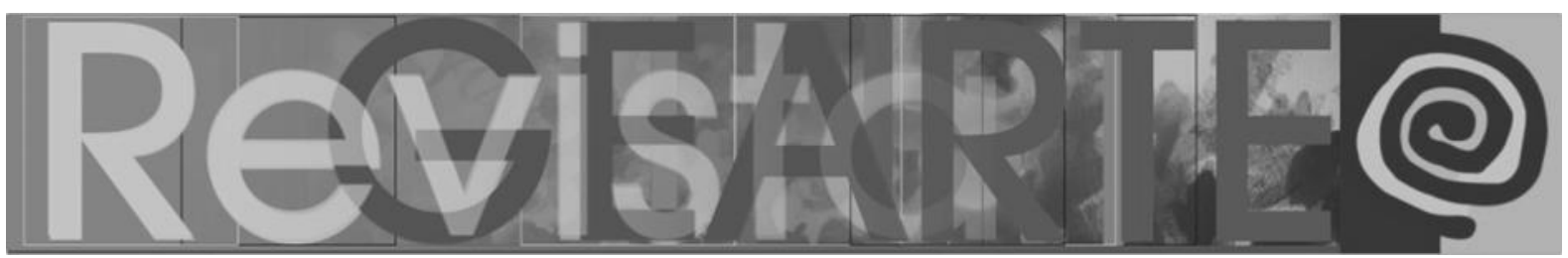

de fundição e preparação de ligas metálicas, sua conformação em fios e chapas, tratamentos decorativos de superfícies foram desenvolvidos já com maestria pelos povos antigos como os sumérios e egípcios e são empregados até hoje. As técnicas de lapidação basicamente seguem cânones formais para a produção de objetos que têm como finalidade refletir a luz incidente.

Essa linguagem formal, associada às novas tecnologias envolvidas na produção joalheira, como a modelagem virtual ou tridimensional, trazem novos diferenciais, que, se utilizados de forma complementar aos processos tradicionais, podem contribuir para a construção de novas formas e significados.

A conjugação de todos esses aspectos permite reforçar diversos atributos das joias, como a valorização do trabalho artesanal enquanto referência da qualidade dos objetos, evidenciada pelo domínio das técnicas.

\section{O fazer-manual no ensino}

A temática apresentada neste artigo tem sido conduzida no ensino por meio de um grupo de estudos de pesquisa e extensão que tem como intuito investigar a fabricação manual de acessórios eletrônicos inteligentes.

O grupo de estudos formado aborda processos construtivos com técnicas tradicionais da indumentária, como costura e bordado, com procedimentos de modelagem e impressão 3D para criar joias digitais e vestimentas eletrônicas sensíveis ao corpo e ao ambiente. Sua proposta conceitual pode ser representada com a noção do casulo, que é uma pele-membrana que protege, mas que também possibilita a metamorfose da forma/estrutura/subjetividade corpórea, capacitando o "antigo corpo" para novas possibilidades e afetos.

Os temas de pesquisa deste grupo estão relacionados à computação vestível e afetiva, e sua relação com a arte, artesanato e eletrônica. São pesquisados materiais para a construção de objetos com técnicas tradicionais como costura, tecelagem e bordado, e também por meio da joalheria experimental interativa, com 


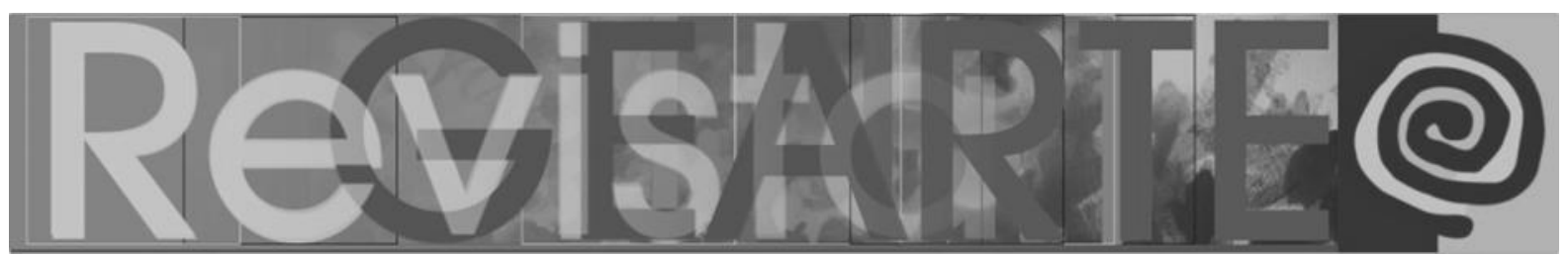

modelagem e impressão de peças $3 d$ com eletrônica embutida. Esses tópicos abarcam diferentes formatos de ensino e a aprendizagem de arte digital.

A prática do grupo inclui prototipagem eletrônica básica e introdução à programação, combinada com discussão teórica-conceitual sobre os termos e aplicações em projetos de roupas e acessórios vestíveis interativos. Os participantes decidem previamente o conteúdo a ser discutido e optam por estudar referências bibliográficas em artigos, livros, palestras e vídeos. Todos os membros estudam o material e se preparam para a discussão conduzida em um dia no qual se apresenta o que foi feito nos projetos realizados de forma individual. Coletivamente, são conduzidos encontros voltados às práticas de projetação eletrônica onde cada participante decide por ingressar em um ou mais projetos sobre computação vestível que estão sendo desenvolvidos.

Em seu primeiro ano, o grupo se dedicou à investigação de vestimentas e acessórios interativos que reagem aos estados de emoção do usuário. As principais propostas que surgiram no grupo foram relacionadas aos seguintes temas: a) pesquisa sobre galvanoplastia, para aplicação em diferentes objetos e superfícies, e criação de joias interativas e tecidos condutivos; b) pesquisa sobre pigmentos eletrotérmicos que reagem à tensão aplicada e tecidos que mudam de cor; c) estudos sobre sensores têxteis, seus desenhos e esquemas; d) criação de um livro interativo têxtil de computação vestível, com desenhos de esquemas eletrônicos e projetos simples com material flexível; e) captura de dados da internet, internet das coisas e integração com redes sociais; e) estudo sobre roupas e sensores de perigos ambientes; poluição do ar, calor excessivo, dentre outros; f) desenvolvimento de um kit para facilitar a criação de computadores vestíveis.

O grupo está concentrado no momento na construção de seus próprios componentes eletrônicos, com o objetivo de desenvolver um conjunto de pequenos módulos eletrônicos. Esses módulos, alguns dos quais serão pré-programados, irão compor um kit de eletrônica têxtil, que permitirá interligar processos artísticos, 


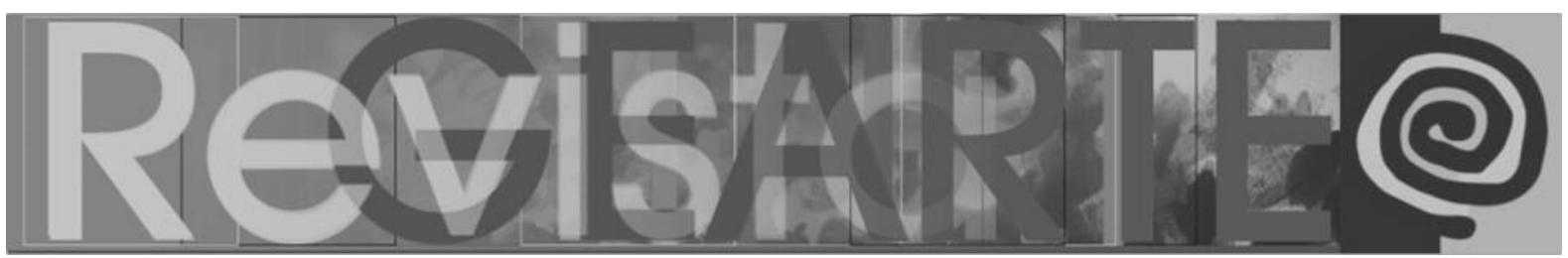

de design, de eletrônica e ciência da computação para o ensino-aprendizagem de diferentes públicos. O objetivo principal com isso é que se tenha uma espécie de "material didático para computação vestível", composto de módulos acopláveis, que podem ser implementados em diversos circuitos, para diferentes projetos que envolvam tecnologias vestíveis têxteis. Acreditamos que a introdução de novos processos, materiais e ferramentas à eletrônica e à ciência da computação pode tornar o tema mais interessante para novos públicos.

O suporte tecnológico nessa experimentação para a criação de acessórios pessoais "inteligentes" é baseado em Arduino, uma plataforma de hardware e software livre que permitiu que o processo de construção de objetos interativos e sensíveis ao ambiente fosse mais viável para artistas, designers e estudantes. Assim, componentes eletrônicos podem ser aplicados em diferentes projetos e experimentações, como, por exemplo, para incluir luzes em uma peça de roupa ou acessório, sensores de diversos tipos, sons, entre outras possibilidades. Com essa abordagem, existem disponíveis no mercado conjuntos de ferramentas para computação física que buscam diminuir a distância entre a programação e a construção de eletrônicos, como o PicoCrickets, elaborado para o ensinoaprendizagem de eletrônica e expressão artística para crianças.

O Arduino LilyPad, por sua vez, é um conjunto próprio para a eletrônica têxtil, criado pela engenheira norte-americana Leah Buechley. Esse kit composto de módulos eletrônicos em pequenas placas finas, com menos de um milímetro de espessura, possui um pequeno computador programável e componentes com forma circular e furos que permitem sua costura com linhas condutivas. Essa plataforma eletrônica foi projetada para a criação de computação vestível e é considerada uma ferramenta própria para a vestimenta, pois é pequena, lavável, de código e hardware abertos ${ }^{1}$.

A eletrônica têxtil é uma prática que busca integrar de modo fluido materiais flexíveis e pequenos como tecidos, linhas, nessas áreas aparentemente 


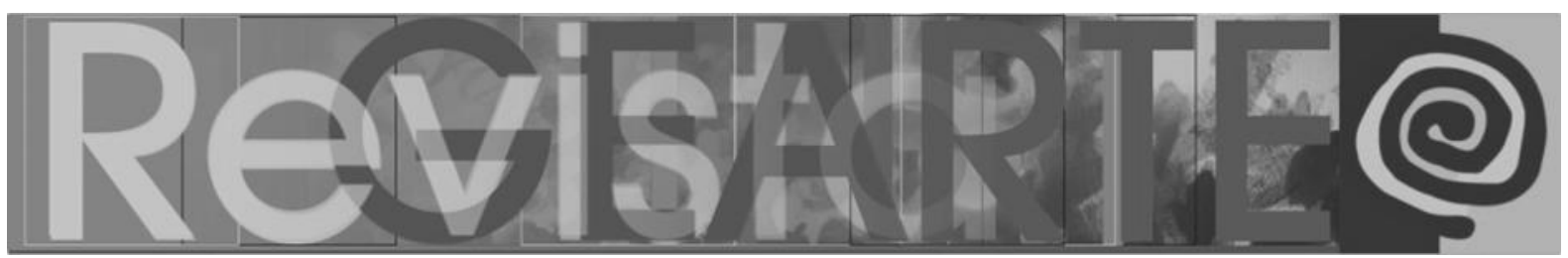

incompatíveis. Essa mescla entre fios elétricos e costura, programação e bordado, além de possibilitarem a construção de têxteis eletrônicas pessoais, também introduzem novos processos e novos modos de fazer e pesquisar arte e tecnologia.

Essa construção individual apresenta outra abordagem com os eletrônicos, pois, estando fora da produção industrial, se associa à expressão pessoal e à criação estética. No grupo, o ensino de bordado e costura traz o foco no processo, pois a construção proposta não busca outra tecnologia, mas sim novas associações. O grupo está interessado em desenvolver novas formas de criar objetos que alcancem resultados diferentes dependendo do seu criador. $\mathrm{O}$ intuito da utilização desses kits está mais na observação e reflexão sobre o processo, pois a construção de cada módulo com diferentes pontos de bordado permite individualizá-los de uma forma pessoal. Essa aproximação é diferente do emprego simples dos componentes eletrônicos disponíveis no mercado, que são padronizados, fabricados em massa, otimizados para a velocidade, eficiência e repetição da montagem.

A abordagem do kit de eletrônica têxtil enfatiza a construção desses sistemas, seu processo de criação solicita a demora, a concentração, o envolvimento motor do corpo e da mente. O seu modo de produção deixa marcas da personalidade e do estado emocional do criador. Os pontos "corridos" ou pontos "perfeitos" podem apresentar traços desses estados, entre outras marcas do fazer que são impressas em cada elemento. Desse modo, entende-se que as peças finais que usaram em sua construção os mesmos componentes básicos, por serem criadas por pessoas diferentes, nunca serão iguais.

Nesse ponto, cabe questionar sobre a poética desses pequenos módulos de bordados eletrônicos, como os ilustrados na Figura 2. Acreditamos que há uma poética no processo de "demorar-se", de contar os pontos, de desfazer os nós e refazer outra vez. Esse é um aspecto interessante da "funcionalidade" desses módulos bordados para o ensino de arte e tecnologias artesanais. Eles terão a 


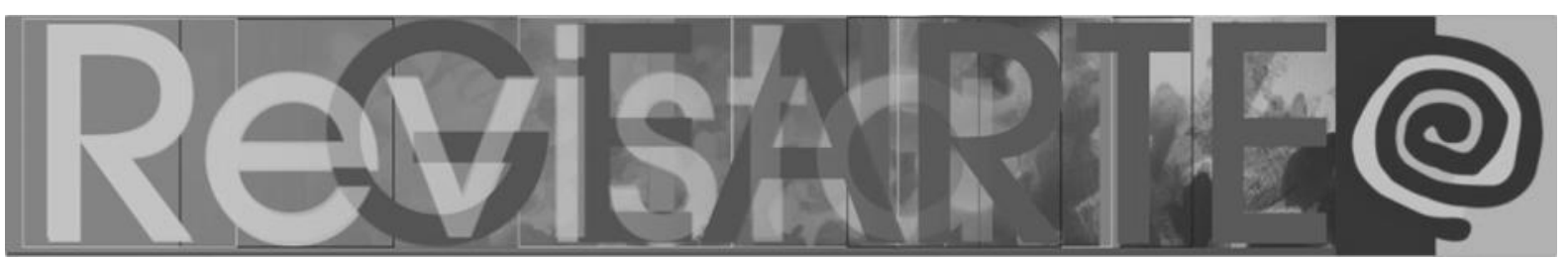

função de fornecer energia, modificar sua condução, diminuir a tensão em determinadas partes do circuito, criar chaves (ligado ou desligado), enfim, cumprir diferentes papéis em um circuito eletrônico têxtil. Além disso, são criados com o intuito de compor um kit que permitirá que sejam costurados e descosturados em diferentes projetos têxteis, para facilitar o processo de ensino aprendizagem de eletrônica e computação para pessoas sem conhecimento prévio nessas áreas.

Figura 2 - Eletrônicos bordados para criação de um kit de eletrônicos têxteis. Microcomputador Lilypad Arduino, baterias, carregador de bateria, e sensor de dobra
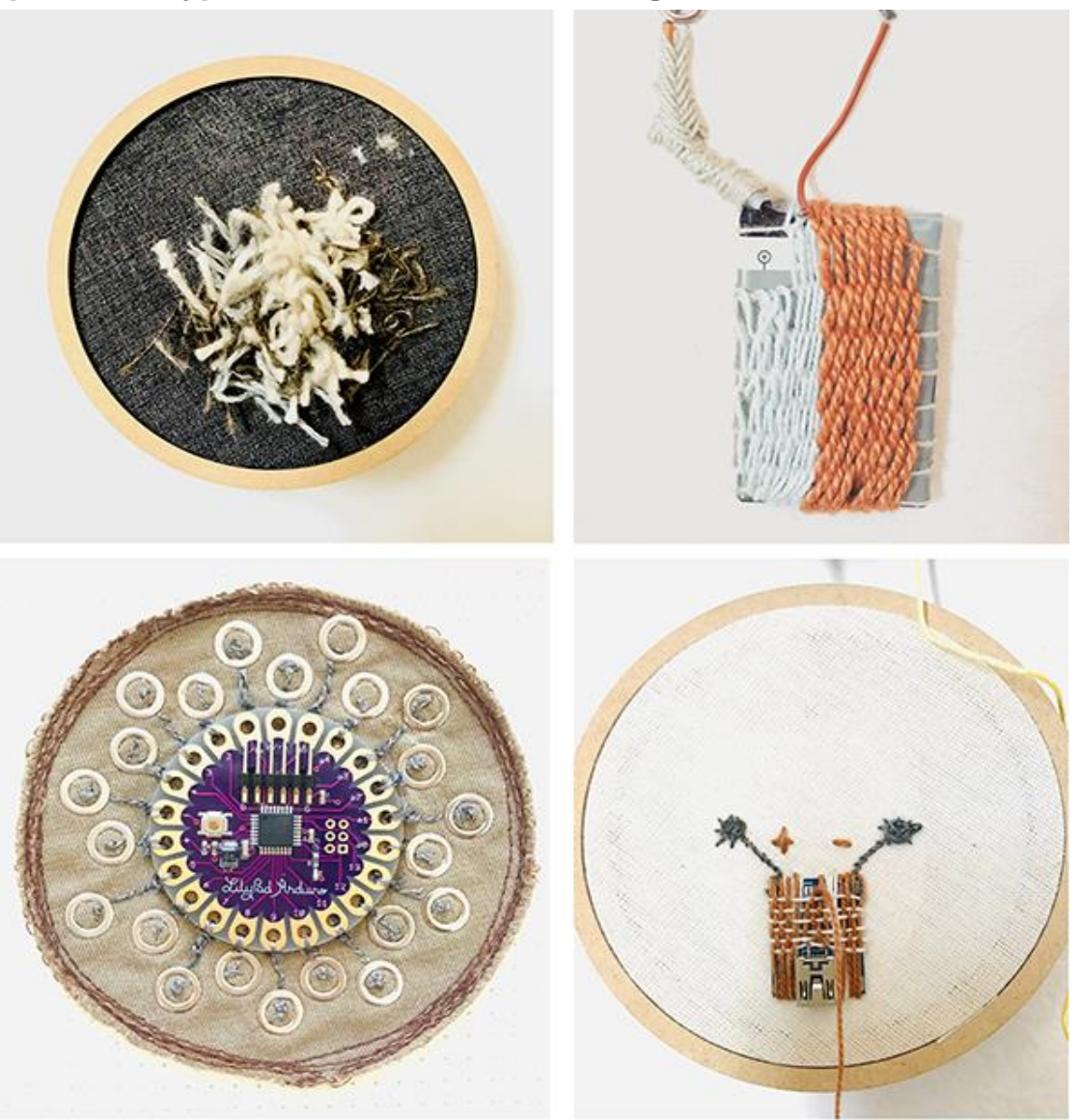

Fonte: Thatiane Mendes (2020).

Criar nossas próprias ferramentas é um modo de nos desprender das estruturas rígidas e duras dos nossos aparelhos cotidianos e seus componentes. Mas também é uma forma de nos instrumentalizar, tendo em vista que a junção entre eletrônica, bordado e costura é uma relação recente, para a qual instrumentos, processos e ferramentas ainda estão sendo criados. 


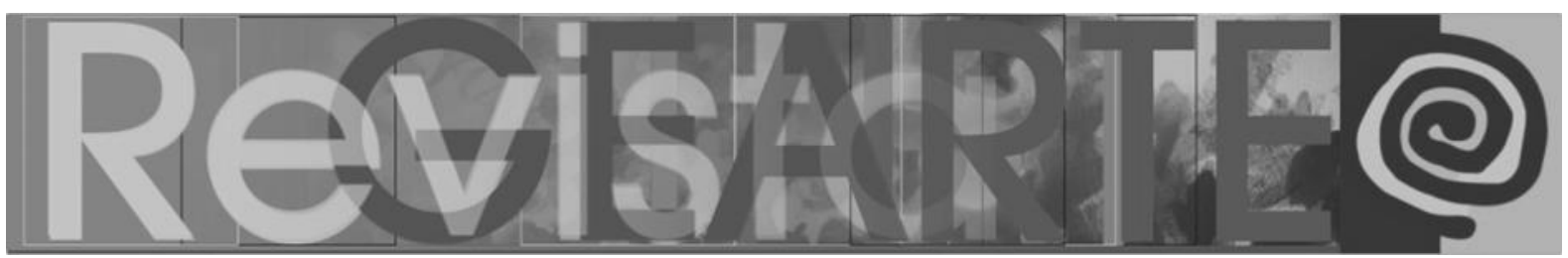

Como professores de arte, sabemos que não há materiais didáticos que consigam abarcar as possiblidades poéticas do fazer artístico e constantemente nos deparamos com a necessidade de criar nossas próprias ferramentas. Por isso, nos pautamos na prática da $A / R /$ tografia, método emergente de pesquisa em arte/educação baseado na inter-relação entre fazer artístico e pesquisa, uma forma de mesclar a prática artística à prática docente.

\section{Aplicações em poéticas tecnológicas}

A experimentação com esses módulos eletrônicos e artefatos no desenvolvimento de acessórios sensíveis pode ser ilustrada nesse contexto com as peças da obra Futura pele, de Thatiane Mendes, exposta em 2019.

Futura pele é constituída dos acessórios sensíveis: 1) bússola tátil: narrativas do caminhar; 2) empalidecer: narrativas do afeto; assim como do processo de construção das peles tecnológicas que as constituem através de um processo denominado; 3) mauna. Em mauna, a artista busca investigar formas de criar memórias de intimidade sobre seu corpo, realizando uma série de experimentos para memorizar o espaço por meio de sensores diversos, de qualidade do ar, luz, som, temperatura a batimentos cardíacos. Mauna, prática do silêncio na Yoga, tem como intuito o "jejum da fala" para melhor observar o próprio corpo. A proposta é realizar exacerbadamente registros imagéticos dos locais visitados, por meio de fotografias e vídeos, e, ao fazer esses registros, "apagar" ou "adormecer" os demais, o objeto é criar uma "distância" daquele local em termos sensoriais. 


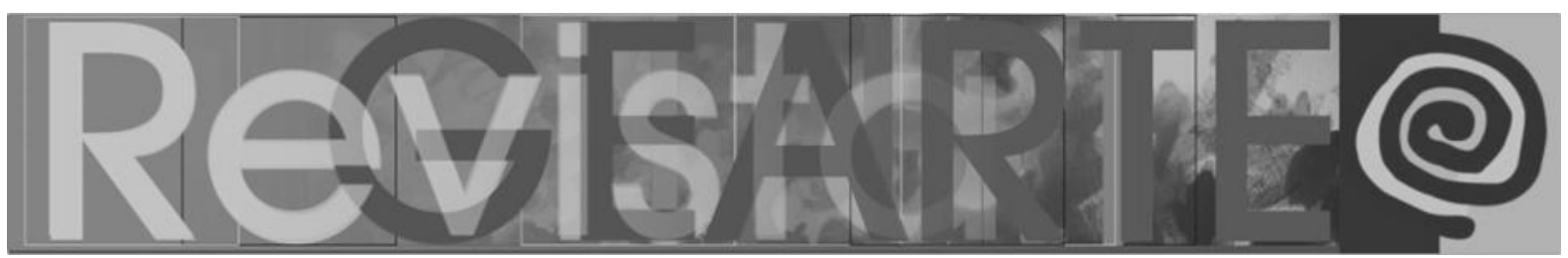

Figura 3 - Bussola tátil

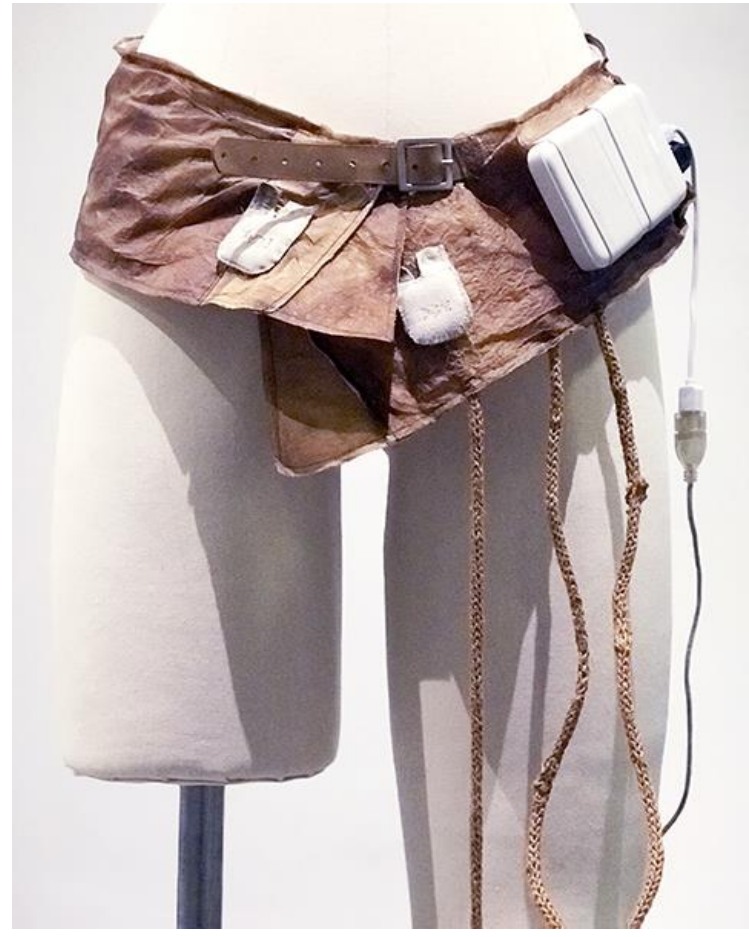

Fonte: Thatiane Mendes (2020).

O cinto bússola tátil: narrativas do caminhar (Figura 3) cria um tipo de "mapa sensorial" para ser sentido no corpo em ação. O cinto registra o trajeto realizado durante o deslocamento. Interessa, neste sentido, identificar a poética do ato de andar com a presença e memória no espaço físico. Teve como ponto de partida descobrir como uma roupa poderia "memorizar" o trajeto realizado pelo corpo e depois como apresentar esse mesmo trajeto realizado, reproduzindo esses dados em forma de "memórias físicas", para serem sentidas sobre a pele e/ou roupa de outra pessoa e/ou em outro momento.

Empalidecer: narrativas do afeto procura criar sensações hepáticas similares àquelas causadas pelos instintos naturais de empalidecer, o arrepio dos pelos no pescoço, calafrios etc. Como se as sensações de perigo fossem experimentadas a partir de um "instinto artificial". A obra empalidecer (Figura 4) tenta trazer de volta algo que se perdeu: a empatia e a reação física perante os perigos, desastres, catástrofes e injustiças sociais. Trata-se de um dispositivo para afecção. Uma joia que captura movimentos cardíacos e reage movimentando uma 


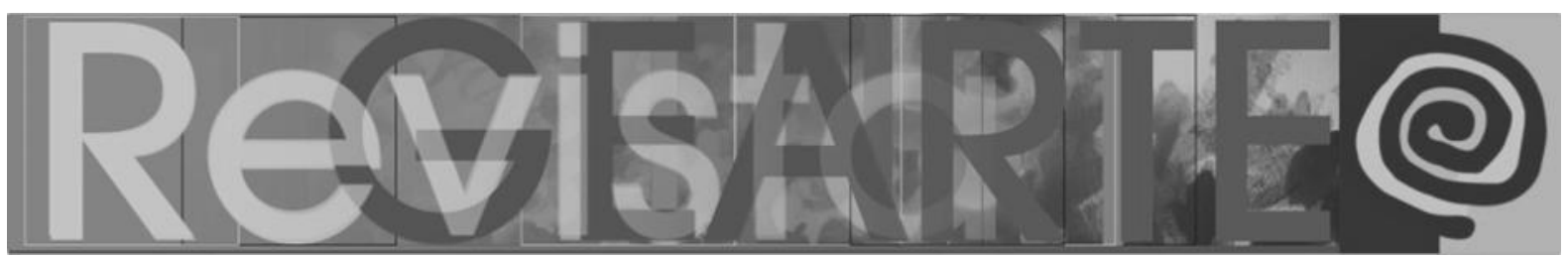

pele sobre ela e alterando a cor de outro dispositivo-pele a ela conectada. Esta outra pele se ruboriza e se empalidece com relação aos dados da joia.

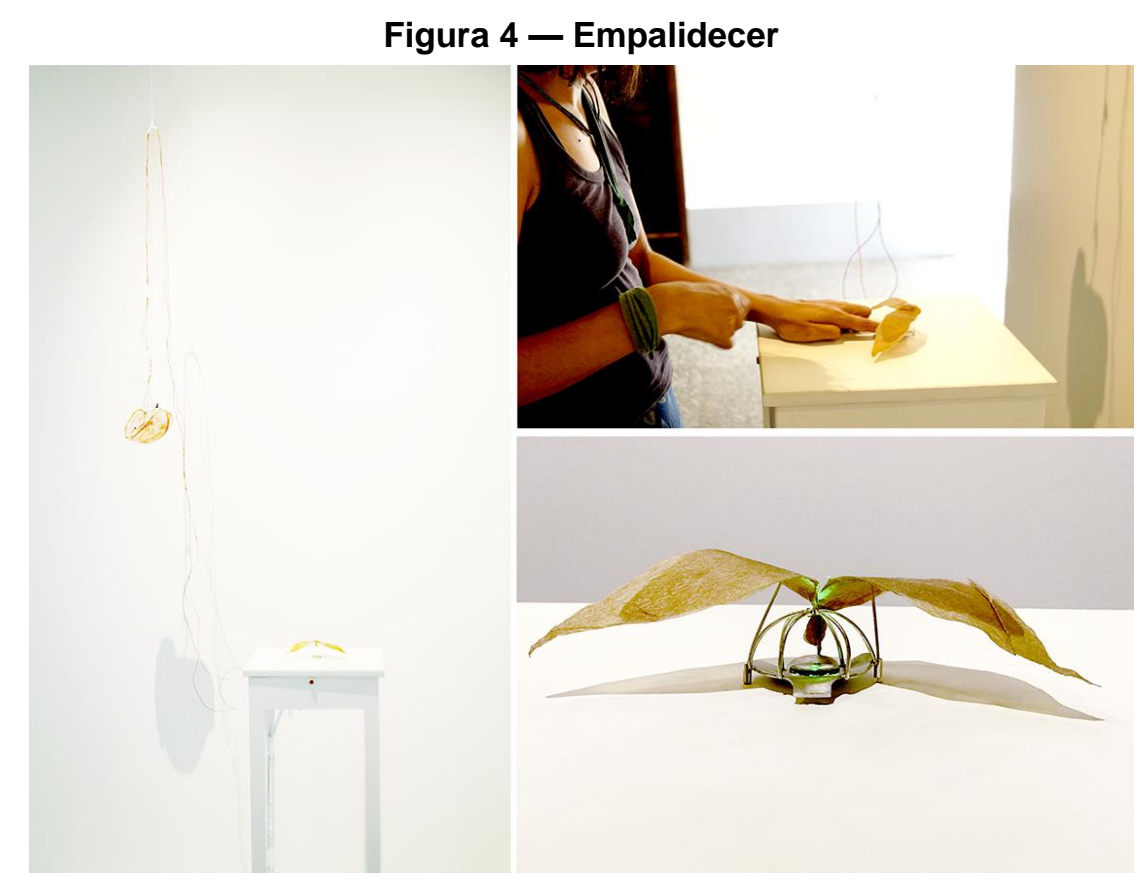

Fonte: Thatiane Mendes (2020).

Para a construção dessas peças foi "cultivado" um tecido-pele a partir de uma estrutura viva formada por microrganismos que se alimentam de um liquido. Nesse líquido é formada uma camada gelatinosa em sua superfície. Quando seca ela se transforma em uma membrana semelhante a uma pele/couro, gerando um biotecido menos nocivo ao corpo e ao meio ambiente, com características da epiderme humana: rugas, coloração, textura, marcas do tempo e sulcos, fazendo alusão à aproximação das tecnologias ao corpo humano.

Seu contexto é se colocar no lugar do outro, ou no lugar onde o outro esteve. Perceber que ações do nosso cotidiano podem ser reproduzidas ou narradas com uma exatidão tamanha a ponto de mostrar exatamente quantos passos uma pessoa realizou e em qual direção. Tais dados referentes à orientação espacial, baseados na interpretação e registro do simples ato de caminhar, podem dizer muito sobre um indivíduo: onde, quando, com quem esteve e por quanto tempo, entre outras informações que consideramos de intimidade sobre o corpo. 


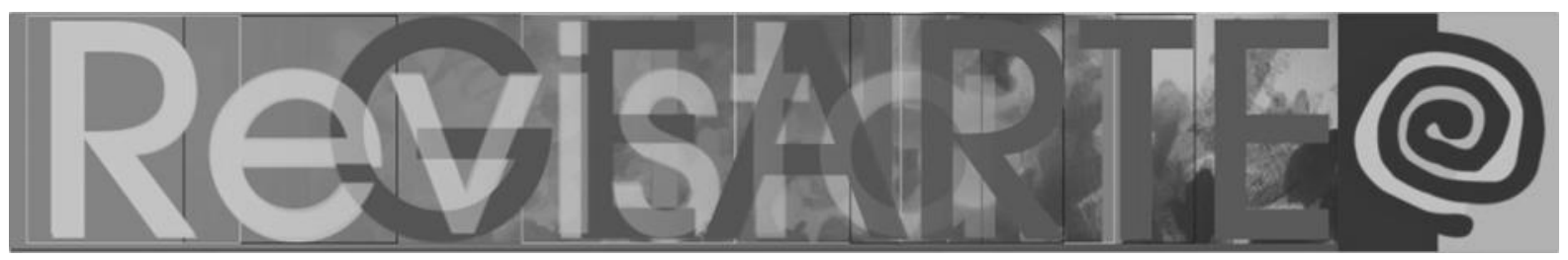

\section{Conclusões}

Como fazer emergir essas narrativas sem destituí-las de toda a sua potência, de sua carga hermética e misteriosa? Essa vem sendo uma tarefa que as "futuras peles" e os novos processos e ferramentas para ensino de arte e tecnologias parecem estar reivindicando para si. Peles, costuras e bordados eletrônicos mais adaptados a esta nova relação corpo-máquina. E mais biológicas, possibilitando a aproximação entre indivíduos com o mundo ao invés de afastá-los. Elas geram novas possibilidades sensoriais, ao invés da apatia sensorial, que possibilita o conhecimento de si e não somente das histórias do outro, e que possibilita o registro diário e "autobiogravação" subjetiva ao invés do melhoramento físico do corpo.

Esses tipos de dados, quando capturados por tecnologias vestíveis sobre a pele, escapam à vontade sobre o que a pessoa quer registrar ou narrar sobre sua história, sendo algo involuntário. Trata-se de uma história narrada pelo dispositivo a seu modo, não cabendo mais edições sobre a exposição da vida pessoal, como se faz ao publicar fotos, vídeos, sons e textos em redes sociais. Tais amostras do dia a dia, se publicadas em redes sociais, teriam outra estética, muito diferente das conhecidas até agora. Amostras de intimidade, às vezes sem foco, grande quantidade de dados, tempos "alongados" e dilatados pela falta de cortes e edições, repetições, entre outras características advindas da cultura do algoritmo.

Neste contexto, as máquinas vêm assumindo um papel de "guardar" uma grande quantidade de memórias sobre nossas vidas, não só em forma de imagens e sons, mas de dados baseados nos aspectos internos do nosso corpo. Essas informações dizem respeito, por exemplo, à circulação e ao movimento dos líquidos internos do corpo, à temperatura da pele, aos lugares onde se esteve, à umidade ou à qualidade do ar onde esse corpo esteve, aos aspectos de luminosidade dos espaços internos e externos; e aos demais dados sobre o corpo e seu contexto. 


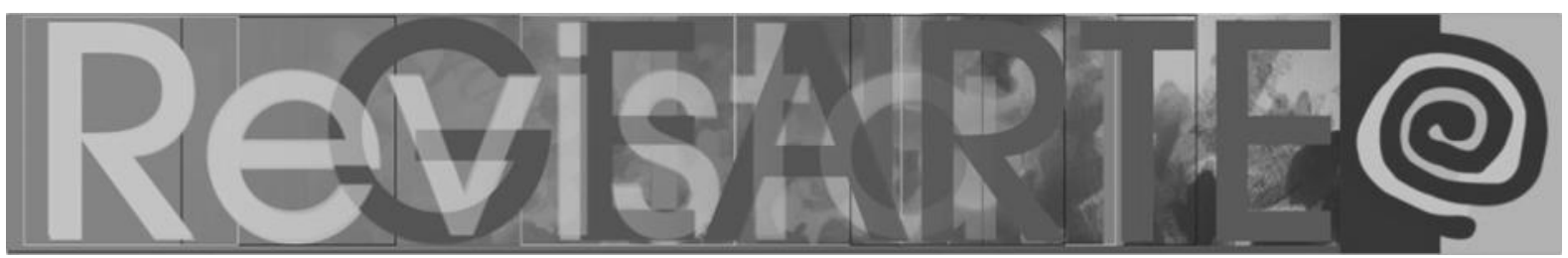

Devemos dar mais atenção para essas narrativas que já vêm sendo criadas sobre nós mesmos, construídas pelas tecnologias de computação vestível e outras, anexas ao corpo-veste, como os smartphones. Pois tais narrativas podem dizer muito sobre nós, aspectos que ainda desconhecemos.

Para isso temos buscado identificar outros modos de construção (mais pessoais) e interpretação dessas narrativas criadas pelos computadores vestíveis. Estes elementos silenciosos que atuam sobre nossas peles e que parecem agora seres ou criaturas pequenas, coladas na superfície de nosso corpo e no tecido da nossa roupa, em completa sintopia. Sintopia porque é algo para além da sintonia, pois trata-se de uma relação corpo-tecnologia que se tornou biológica, tamanha a intimidade com que essas maquininhas têm lidado com os aspectos subjetivos e físicos da vida humana, modificando-se assim como nos modificamos também e adaptando-se um ao outro. Como o tecido da roupa, que vai tomando a forma e o calor do nosso corpo. E o corpo que também vai tentando preencher os espaços destes tecidos-vestimentas. Entre a pele, os tecidos e a roupa pode haver muitas histórias escondidas.

\section{Nota}

1 Software e hardware livre apresentam um conjunto de licenças que incentivam à colaboração a partir da disponibilização gratuita e livre da informação sobre o projeto de hardware (artefatos tangíveis), layout da placa e diagrama dos componentes para seu melhoramento. Deste modo acontece com o código aberto, que disponibiliza informações a fim de fomentar o aperfeiçoamento do código-fonte do software.

\section{Referências}

CASTILHO, Kathia. Moda e linguagem. São Paulo: Anhembi Morumbi, 2004.

MANN, Steve. Wearable computing: a first step toward personal imaging computer. IEEE Computer, Washington, DC, v. 30, n. 2, p. 25-32, 1997.

MCKELLAR, Susie; SPARKE, Penny. Interior design and identity. Manchester: Manchester University Press, 2004.

MCLUHAN, Marshall. Os meios de comunicação de massa como extensões do homem. São Paulo: Cultrix, 1964.

MENDES, Thatiane; SALLES, Vanessa Madrona Moreira. Corpo humano em sintonia com a computação vestível. Pós, Belo Horizonte, v. 5, n. 10, p. 84-93, 2015.

DUQUE, Thatiane Mendes; MOL, Adriano Aguiar. O fazer-manual de acessórios 152 eletrônicos sensíveis: uma abordagem interdisciplinar de arte, moda e design. Revista GEARTE, Porto Alegre, v. 8, n. 1, p. 134-153, jan./abr. 2021.

Disponível em: http://seer.ufrgs.br/gearte 


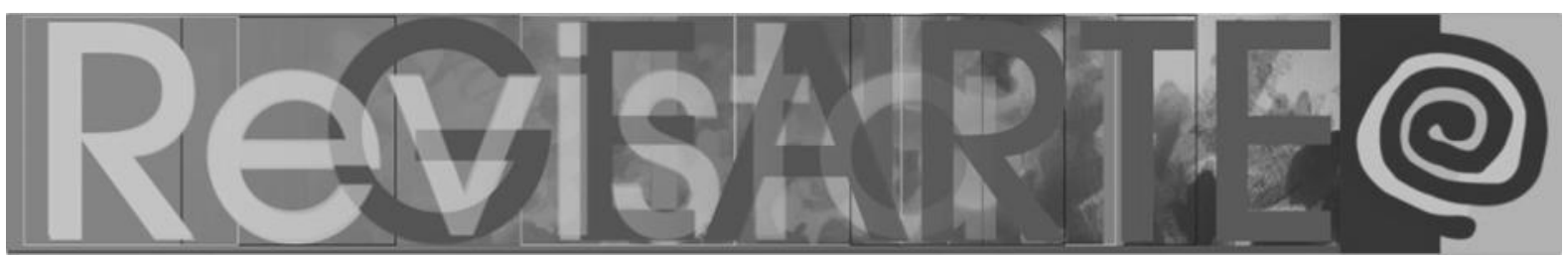

PICARD, Rosalind. Affective computing. Massachusetts: MIT Press, 1998.

SOARES, Maria Regina Machado. O design de jóias entre a tradição da permanência e a invenção da obsolescência. In: CONGRESSO INTERNACIONAL DE PESQUISA EM DESIGN, 1., 2002, Brasília, DF. Anais [...]. Brasília, DF: Laboratório de Estudos Integrados em Arquitetura, Design e Estruturas, 2002.

VILLAÇA, Nízia. A edição do corpo: tecnociência, artes e moda. São Paulo: Estação das Letras e Cores, 2011.

WALLACE, Jayne. Journeys. 2006-2007. Jayne Wallace, [s. I.], 2018. Disponível em: https://www.jaynewallace.com/travel. Acesso em: 10 maio 2020.

\section{Thatiane Mendes Duque}

Professora pesquisadora na Escola de Design da Universidade do Estado de Minas Gerias (UEMG). Coordenadora do Grupo Casulo - arte, design e tecnologias vestíveis sediado no Centro de Estudos em Design de Gemas e Joias CEDGEM. Doutora em Poéticas Tecnológicas pela Universidade Federal de Minas Gerais (UFMG). Mestre em Produções Artísticas e Investigação pela Universidade de Barcelona, Espanha (2010). Bacharel, com Licenciatura Plena, em Artes Visuais pela Universidade Federal de Uberlândia (UFU) (2007). Em 2013 fundou a startup Triskel que se baseia na criação de acessórios e roupas com computação vestível. Triskel foi selecionada e premiada pela aceleradora Startups and Entrepreneurship Ecosystem Development (SEED). Recebeu o prêmio em primeiro lugar no XVI Salão Nacional de Arte de Jataí em 2017, com a escultura vestível interativa: Jaula, e o prêmio Programa CoMciência - arte, ciência e tecnologia.

ORCID: https://orcid.org/0000-0002-4325-7346

E-mail: thatiane.duque@uemg.br

Currículo: http://lattes.cnpq.br/1033054009313345

\section{Adriano Aguiar Mol}

Doutor em Engenharia de Materiais pela REDEMAT (2016). Especialista em Design de Gemas e Joias pela Escola de Design/UEMG (2001). Graduado em Artes Plásticas pela Escola Guignard da Universidade do Estado de Minas Gerais (2000), com prévia graduação interrompida em Economia (UFMG, 1992-1994). Atuou por quinze anos na indústria e comércio de gemas e joias em nível nacional e internacional. Foi premiado em concursos de design de joias no Brasil, Bélgica e Hong Kong. Desde 2005 é professor da Escola de Design da Universidade do Estado de Minas Gerais/UEMG, onde desenvolve projetos de ensino, pesquisa e extensão, com interesse nos seguintes temas: design de lapidação, gemologia e design de joias. Gestor de projetos de design aplicado ao setor e coordenador técnico da Pós-Graduação Design em Gema s e Joias desde 2007. Coordenador do Centro de Estudos em Design de Gemas e Joias da Escola de Design desde 2018.

ORCID: https://orcid.org/0000-0003-4828-2513

E-mail:mol.adriano@gmail.com

Currículo: http://lattes.cnpq.br/9175837846207524

Recebido em 29 de maio de 2020 Aceito em 15 de outubro de 2020 